\title{
Efficiency Analysis of the Turkish Red Crescent between 2012 and 2014
}

\author{
Aşır Özbek ${ }^{1}$ \\ ${ }^{1}$ Vocational School, Kırıkkale University, Kırıkkale, Turkey \\ Correspondence: Aşır Özbek, Vocational School, Kırıkkale University 7. Km, Ankara Yolu, Kırıkkale, Turkey. \\ Tel: 0-544-824-8903. E-mail: ozbek@kku.edu.tr
}

Received: July 1, 2015

Accepted: July 24, 2015

Online Published: August 25, 2015

doi:10.5539/ijef.v7n9p322

URL: http://dx.doi.org/10.5539/ijef.v7n9p322

\begin{abstract}
Like businesses with commercial purposes, non-governmental organizations (NGOs), such as the Red Cross and the Red Crescent, should also be in a constant search for more funds to provide help for more people. Otherwise, they will, in the long term, either shut down or start operating inefficiently, which is not sustainable. Therefore, NGOs also must work efficiently, and should check their performances by going through efficiency analyses at regular intervals to ensure sustainability. They should take the necessary structural and financial precautions based on the results provided by these performance analyses.

In this study, the efficiency of the Turkish Red Crescent Society (TRC), founded in1868, was measured by an integrated model combining various methods such as Data Envelopment Analysis (DEA), Efficiency Analysis Technique with Output Satisficing (EATWOS), and the Competitiveness Operational Rating (OCRA). The comparison of the results provided by these methods indicated that TRC did not show a high performance in 2012 while the efficiency was found to be better in 2013 and 2014.
\end{abstract}

Keywords: non-governmental organizations, efficiency analysis, data envelopment analysis, EATWOS, OCRA, Turkish Red Crescent Society

\section{Introduction}

All organizations must constantly renew themselves while carrying out their activities. To make their presence permanent, they need to follow a transformation policy to adapt to changing circumstances. This is also true for non-governmental organizations (NGOs). They must keep themselves ready for necessary changes as well and take remedial measures not to experience difficulties in maintaining activities in the long-term.

Established for a particular purpose by individuals working on a voluntary basis, NGOs are non-profit organizations funded by donations and/or membership dues. NGOs are such organizations as chambers, trade unions, associations and foundations. The Turkish Red Crescent Society (TRC) is an NGO established for a social purpose. TRC was founded on June 11, 1868 as "the Benefit Society for the Wounded and Sick Ottoman soldiers". Continuing its activities under various names until 1947, when the name was changed to the "Turkish Red Crescent Society", it is now an international aid organization, extending a helping hand to every corner of the world. TRC is a non-profit, voluntary, social service organization with legal personality, subject to the provisions of private law, and provides help and services free of charge. The organization of TRC is comprised of headquarters and branch offices. All tasks and services at all levels except for the ones at the headquarters are voluntary. Among the goals of TRC are to prevent or alleviate the suffering of the people wherever necessary, to protect the lives and health of people anywhere and everywhere, without any discrimination, and to bring mutual understanding, friendship, respect, cooperation and lasting peace to the world (K1zılay.org.tr.).

The total income of TRC in 2014 was about US\$203 million. About 68 million dollars were used in line with organizational goals. In other words, approximately 33\% of this amount was spent on social purposes. 58\% was transferred to the costs. The amount allocated to social purposes could be considered very low. This might suggest that TRC works inefficiently. The funds allocated to social purposes needs to be increased. Therefore the efficiency of TRC needs to be increased.

For-profit or non-profit, all organizations should conduct efficiency analyses at regular intervals to see and rectify the weaknesses. Non-profit organizations should also take it as seriously as businesses, for it is important 
to efficiently use the funds collected from benefactors in accordance with the purpose. Otherwise, they will fall into disrepute and have to cease to exist eventually.

This study measured the efficiency of TRC, an NGO, between 2012 and 2014 using an integrated model combining the Data Envelopment Analysis (DEA), the Efficiency Analysis Technique with Output Satisficing (EATWOS) and the Competitiveness Operational Rating (OCRA). No such study, related to the efficiency of an NGO, has been found in the literature. This study is believed to be the first of its kind. "Total Revenues" and "Total Expenses" were taken as inputs while "the Total Expense for Goals and Services" and "Surplus Income" were defined as the output criteria.

The rest of this paper will include section 2, which introduces literature review, section 3, which presents the methodology, and section 4, which introduces data and discussion of the results. Conclusions are shown in section 5 .

\section{Literature Review}

Most of the literature on NGOs deals with their history and activities. Within the literature, however, there is little explicit analysis of the normative ideals that underpin performance measurement and evaluation practices in third sector organizations (Bouchard, 2009a, b; Eme, 2009).

The literature review done for the present study has revealed that other than Berber et al. (2011), there is no study, where DEA, EATWOS and OCRA were used separately or integrated, related to the assessment or efficiency analysis of NGOs. The present article, in order to fill the gap in the literature, focuses on the methodological issues of performance evaluation of NGOs.

DEA can be employed for different purposes in different areas. Therefore, there are many studies having used DEA methodology in the literature. The present article offers a few examples of DEA, notably in social issues. For instance, Kirigia et al. (2004) used DEA to measure the technical efficiency of public health centres in Kenya. Gutierrez-Nieto et al. (2007) measured the efficiency of microfinance institutions (MFI) with both a social nature and a for-profit nature. The analysis included thirty Latin American MFIs from Bolivia, Colombia, Dominican Republic, Ecuador, Mexico, Nicaragua, Peru and Salvador. Haq (2010) measured the cost efficiency of 39 non-governmental MFIs across Africa, Asia and the Latin America using non-parametric DEA. Kirigia et al. (2011) employed DEA to assess the technical efficiency of primary health units in Kailahun and Kenema Districts of Sierra Leone. Blaakman et al. (2014) used DEA to measure the technical efficiency and cost efficiency of the Basic Package of Health Services, a project carried out by Afghan Ministry of Public Health and international NGOs in 2008 and 2009 in 31 of the 34 Afghan provinces. Lépine et al. (2015) used DEA to find the determinants of technical efficiency of a large scale HIV prevention project "Avahan", implemented in India by NGOs. Wijesiri et al. (2015) employed a two-stage double bootstrap approach, which is a DEA application, to measure the technical efficiency of 36 MFIs in Sri Lanka. Widiarto and Emrouznejad (2015) proposed a two-stage DEA method to measure the social and financial performance of Islamic Microfinance institutions (IMFIs) by comparing them to conventional MFIs.

EATWOS, being a quite new method, has been used effectively in some areas. For instance, it was used by the developers in measuring the efficiency of heat treatment furnaces and supply change (Peters \& Zelewski, 2006; Peters et al., 2012). It was also used by Bansal et al. (2014) in the evaluation of vendors.

OCRA has been implemented in various areas successfully. For example, it was used in the relative operational performance measurement of five hotels (Parkan \& Wu, 1997), and in the relative operational performance of the application software development teams of a large bank in Hong Kong (Parkan et al., 1997). It was also used in the process selection in the manufacturing sector (Parkan \& Wu, 1998) and performance measurement in government services (Parkan, 1999). Other issues where OCRA has been used are as follows: robot selection (Parkan \& Wu, 1999), measurement of the performance of an investment bank (Parkan \& Wu, 1999), competitive analysis of manufacturing plants of processed food industry (Jayanthi et al., 1999), measurement of the operational performance of a public transit company (Parkan, 2002), the performance of drugstore operations (Parkan, 2003), gauging the performance of a supply chain (Parkan \& Wang, 2007), location selection of distribution centers (Chakraborty et al., 2013), material selection (Chatterjee \& Chakraborty, 2012; Darji \& Rao, 2014), and performance analysis of public banks in Turkey (Özbek, 2015).

Though there are many studies related to NGOs in the literature, there is not much research related to the efficiency of them. One of these studies is the evaluation of the effectiveness of non-profit organizations by Murray \& Tassie'nin (1995). Another example is the comparison of the performance of the Bangladesh government and NGOs during and immediately after the flood by Paul (2003). Nanavati (2007) also measured 
the organisational effectiveness of four main NGOs, working for economic empowerment of women in Baroda, on the basis of six main indicators: "financial resources management", "human resources management", "service delivery", "organisational professionalism", "external relations", and "strategic management". Drawing on Kaplan and Norton's (1996) balanced scorecard, and Kolb and Fry's (1975) organisational learning cycle as the conceptual framework, Bull (2007) designed a sector specific business performance measurement tool'Balance'. Ye and Ge (2009) used the balanced scorecard and goal programming methods to evaluate the performance of disaster crisis management of the non-governmental organizations. Ahmed (2010) reports the results of performance and impact evaluation of three community-led library initiatives in Central Thailand. The methodology included both quantitative and qualitative approaches. Campos et al. (2011) evaluated the performance of several NGOs in Brazil. The study examined the results of a two-stage investigation conducted between 2007 and 2009: first, a national study and second, a quantitative and qualitative study made in the state of Santa Catarina. It was a comparative analysis considering the following categories: (i) the principal approaches used; (ii) the role of evaluation; (iii) the main methods of data collection used in each model; (iv) who conducts the evaluations; (v) to whom the evaluation was returned; (vi) the main criteria of evaluation. Berber et al. (2011) suggest a linked, two-stage DEA methodology for assessing efficiency in both charitable fundraising and cause delivery, while empirically investigating results for international aid organizations. The model allows efficiency assessment for both the fundraising and utilization of generated funds when directed for cause-related purposes. Hall (2014) provides a preliminary sketch of the types of logics of evaluation in the third sector, outlining three logics of evaluation: scientific evaluation logic, bureaucratic evaluation logic, learning evaluation logic. Arena et al. (2015) proposed a stepwise method to be used for the performance measurement of social enterprises. Social enterprises can design their own measurement systems by using this method. Among other studies related the performances of NGOs are: Fowler (1996), Kaplan (2001), Bagnoli (2009), Greiling (2009), Bagnoli and Megali (2011), Ebrahim and Rangan (2011), and Ramadan and Borgonovi (2015).

\section{Method}

\subsection{Data Envelopment Analysis}

An advantage of DEA is that it is easy to measure the relative efficiency of decision making units (DMU) in the existence of a multiple-input, multiple-output structure, and it still provides a single performance index. As a mathematical linear programming technique developed by Charnes et al. (1978), it is named the CCR model. The CCR model was proposed by Charnes, Cooper and Rhodes in 1978 under the assumptions of constant returns to scale (CRS). The reduction of multi-output/multi-input position for each unit of production to a single "virtual" output and a single "virtual" input is the fundamental attribute of CCR model. The ratio of the single virtual output to the single virtual input for a particular unit provides a measure of efficiency (Makni et al., 2015). Many theoretical advances and methodological extensions have been added to DEA since the conception of the Constant Returns to Scale (CRS) model. The BCC (Banker-Charnes-Cooper) model developed by Banker et al., allowing for variable returns to scale (VRS), and the slack-based model (SBM), which is unit invariant with an efficiency measure monotone decreasing in each of the slacks of the input and output variables were among the most notable ones (LaPlante \& Paradi, 2015).

In the CCR model, the efficiency value for each DMU is calculated by dividing the weighted sum of the outputs by the weighted sum of inputs. All the values obtained should be equal to or smaller than 1 for all DMUs and the input-output weights should be positive. Under the constraints defined, the efficiency scores for each DM are obtained. The aim is to find the input and output weights that maximize the efficiency score. The CCR model is:

$$
\begin{gathered}
\operatorname{Max}_{k}=\sum_{r=1}^{s} u_{r k} y_{r k} \\
\sum_{r=1}^{s} u_{r k} y_{r k}-\sum_{i=1}^{m} v_{i k} x_{i k} \leq 0 ; j=1,2, \ldots, n \\
\sum_{i=1}^{m} v_{i k} x_{i k}=1 ; j=1,2, \ldots, n \\
u_{r k} \geq 1 ; r=1, \ldots, s \\
v_{i k} \geq 1 ; i=1, \ldots, m
\end{gathered}
$$

where $h_{k}$ is the DMU; $u_{r k}$ is the weight of the output $r ; v_{i k}$ is the weight of input $i ; y_{r k}$ and $x_{i k}$ are output quantities $r$ and input quantities $i$ of the kth DMU respectively (Cooper et al., 2011; Özdemir \& Demirel, 2013).

\subsection{Efficiency Analysis Technique with Output Satisficing}

EATWOS is an efficiency analysis method that allows the DMU to go for satisfying solutions rather than optimum solutions while, like DEA and OCRA, it is also employed to assess the maximum profit between output 
and input quantities. It is a new technique developed by Peters and Zelewski (2006) based upon "satisficing" concept. Herbert A. Simon was awarded the Nobel Prize in economics partly for this idea (Simon, 1979). According to this "satisficing" concept, individuals go for satisfactory rather than optimal solutions. When this idea of Simon's is used in efficiency analysis, the result is that an output quantity meeting a certain satisficing level may be judged to be just as good as an output quantity exceeding this satisficing level. Furthermore, in some cases the proposed efficiency analysis technique is capable of identifying efficiency improvement potentials (Peters \& Zelewski, 2006).

The general EATWOS procedure is described as below (Peters \& Zelewski, 2006)

Determination of the inputs and outputs to be taken into account is the first step. In addition, the DMUs to be measured should be determined by the decision maker. Next, as the EATWOS requires, the decision maker has to establish the output quantities $y_{i j}$ as well as the input quantities $x_{i k}$ for all DMUs. So, the quantities $y_{i j}$ of all outputs $j(j=1, \ldots, J)$ of all DMUs $i(i=1, \ldots, I)$ have to be entered into the output matrix $\underline{Y}$.

$$
\underline{Y}=\left[\begin{array}{cccc}
y_{11} & y_{12} & \ldots & y_{1 J} \\
y_{21} & y_{22} & \ldots & y_{2 J} \\
\vdots & \vdots & \vdots & \vdots \\
\vdots & \vdots & \vdots & \vdots \\
\vdots & \vdots & \vdots & \vdots \\
y_{I 1} & y_{I 2} & \ldots & y_{I J}
\end{array}\right] \text { with } y_{i j} \in R_{\geq 0} \quad \forall i=1, \ldots I, \quad \forall j=1, \ldots, J
$$

As each column of this output matrix $\underline{Y}$ corresponds to an output $j$, each row corresponds to a DMU $i$. The way the input matrix $\underline{X}$ is established is the same.

$$
\underline{X}=\left[\begin{array}{cccc}
x_{11} & x_{12} & \ldots & x_{1 K} \\
x_{21} & x_{22} & \ldots & x_{2 K} \\
\vdots & \vdots & \vdots & \vdots \\
\vdots & \vdots & \vdots & \vdots \\
\vdots & \vdots & \vdots & \vdots \\
x_{I 1} & x_{I 2} & \ldots & x_{I K}
\end{array}\right] \text { with } x_{i k} \in R_{\geq 0}, \forall i=1, \ldots I, \forall k=1, \ldots, K
$$

Similar to the process followed for the output matrix, each column of this input matrix $\underline{X}$ corresponds to an input $k(k=1, \ldots, K)$, and each row corresponds to a DMU. Inputs and outputs must be cardinal measures, as EATWOS requires.

EATWOS provides the chance to consider satisficing levels for outputs. This means that the decision maker is capable of determining a satisficing level $S L_{j}$ for each output $j$. In addition, the exogenous assessment of the relative importance weights $v_{j}$ of the outputs as well as the relative importance weights $w_{k}$ of the inputs must be carried out, as EATWOS requires (Peters \& Zelewski, 2006). A scoring technique or Analytic Hierarchy Process (AHP) can also help to determine the importance weights (Saaty, 2004).

Application of EATWOS without consideration of satisficing levels (Peters \& Zelewski, 2006)

As the next step, EATWOS is applied without consideration of satisficing levels. This way, satisficing levels are ignored for all outputs. The output quantities $y_{i j}$ are normalized first. The normalization of the output quantities takes place as in TOPSIS (Hwang \& Yoon, 1981).

$$
\begin{gathered}
\exists i \quad \exists j \quad y_{i j} \neq 0: \quad r_{i j}=\frac{y_{i j}}{\sqrt{\sum_{i=1}^{I} y_{i j}^{2}}} \quad \forall i=1, \ldots, I \quad \forall j=1, \ldots, J \\
\forall i=1, \ldots, I \quad \forall j=1, \ldots, J \quad y_{i j}=0:, r_{i j}=0
\end{gathered}
$$

The normalization process gives the normalized output matrix $\underline{R}$ :

$$
\underline{R}=\left[\begin{array}{cccc}
r_{11} & r_{12} & \ldots & r_{1 J} \\
r_{21} & r_{22} & \ldots & r_{2 J} \\
\vdots & \vdots & \vdots & \vdots \\
\vdots & \vdots & \vdots & \vdots \\
\vdots & \vdots & \vdots & \vdots \\
r_{I 1} & r_{I 2} & \ldots & r_{I J}
\end{array}\right]
$$

Then, for each output $j$, the maximum normalized output quantity $y_{j}^{*}$ is determined on basis of the column vectors of $\vec{r}_{j}$ of the normalized output matrix $\underline{R}$. 


$$
r_{j}^{*}=\max _{i}\left\{\vec{r}_{j}\right\}
$$

The calculation of the distance measures $o p_{i j}$ for the outputs can be carried out on the basis of the matrix $\underline{R}$ and the maximum normalized output quantities $r_{j}^{*}$.

$$
o p_{i j}=1-\left(r_{j}^{*}-r_{i j}\right), \forall i=1, \ldots, I, \forall j=1, \ldots, J
$$

The distance measure $o p_{i j}$ suggests that the smaller the distance of $r_{i j}$ to $r_{j}^{*}$, the closer $o p_{i j}$ is to one. This distance measure is taken as output score.

The normalization of the input quantities is the next step. This process is a similar one to the normalization of the output quantities.

The distance measure $o p_{i j}$ suggests that the smaller the distance of $r_{i j}$ to $r_{j}^{*}$, the closer $o p_{i j}$ is to one. This distance measure is taken as output score.

The normalization of the input quantities is the next step. This process is a similar one to the normalization of the output quantities.

$$
\begin{array}{r}
\exists i \quad \exists k \quad x_{i k} \neq 0:, \quad s_{i k}=\frac{x_{i k}}{\sqrt{\sum_{i=1}^{I} x_{i k}^{2}}} \quad \forall i=1, \ldots, I \quad \forall K=1, \ldots, K \\
\forall i=1, \ldots, I \quad \forall k=1, \ldots, K \quad x=0: \quad s=0
\end{array}
$$

So, the way the normalized input matrix $\underline{S}$ is calculated is similar to way of the normalization of the output matrix.

$$
\underline{S}=\left[\begin{array}{cccc}
S_{11} & s_{12} & \ldots & s_{1 K} \\
S_{21} & S_{22} & \ldots & s_{2 K} \\
\vdots & \vdots & \vdots & \vdots \\
\vdots & \vdots & \vdots & \vdots \\
\vdots & \vdots & \vdots & \vdots \\
s_{I 1} & S_{I 2} & \ldots & s_{I K}
\end{array}\right]
$$

The determination of the minimum normalized input quantity $s_{k}^{*}$ for each input $k$ on basis of the column vectors $\overrightarrow{s_{k}}$ of the normalized input matrix $\underline{S}$ is the following step.

$$
s_{k}^{*}=\min _{i}\left\{\overrightarrow{s_{k}}\right\} \quad \forall k=1, \ldots, K
$$

The calculation of the distance measure for inputs can be done, then, by adding the respective value $s_{i k}$ from the matrix $\underline{S}$ to 1 and subtracting the minimum normalized input quantity $s_{k}^{*}$.

$$
i p_{i k}=1+s_{i k}-s_{k}^{*} \quad \forall i=1, \ldots, I \quad \forall k=1, \ldots, K
$$

It can be concluded from this distance measure that the smaller the distance of $s_{i k}$ to $s_{k}^{*}$, the closer $i p_{i k}$ is to one. The distance measure $i p_{i k}$ must not be zero, so the value 1 is added. The distance measure $i p_{i k}$ is taken as input score, as it is done in the output score.

In order to obtain an efficiency score for each DMU, the input distance measures (input score) and the output distance measures (output score) can be used.

$$
E_{i}=\frac{\sum_{j=1}^{J} v_{j} * o p_{i j}}{\sum_{k=1}^{K} w_{k} * i p_{i k}} \quad \forall i=1, \ldots, I
$$

When $E_{i}$ of a DMU $i$ is low, this means the efficiency is relatively lower than the other DMUs, while $E_{i}$ is high the efficiency is high. These efficiency scores allow preparing a rank order $R$ of the efficiency of the DMUs by sorting the efficiency scores from high to low.

Application of EATWOS with consideration satisficing levels (Peters \& Zelewski, 2006)

In this step, EATWOS with consideration of satisficing levels $S L_{j}$ is applied for at least one of the outputs $j$ with $j \in\{1, \ldots, J)$. The way the outputs without satisficing levels are treated is the same as described in the previous section.

This model uses five logical constraints. This idea belongs to from Yan, Yu, and Cheng (2003). The following five constraints are applied for all outputs for which the decision maker determines satisficing levels:

$$
\left(\frac{S L_{j}-y_{i j}}{S L_{j}}\right)+z_{1} \leq 1
$$




$$
\begin{gathered}
\left(\frac{S L_{j}-y_{i j}}{S L_{j}}\right) * z_{2} \geq 0 \\
z_{1}, z_{2} \in\{0 ; 1\} \\
z_{1}+z_{2}=1 \\
a_{i j}=\frac{y_{i j}}{S L_{j}} * z_{2}+1 * z_{1}=f\left(y_{i j}\right)
\end{gathered}
$$

The constraints (14a) and (14b) are used to restrict the possible values of the logical variables. Constraint (15) describes the logical variables $z_{1}, z_{2}$ as binary variables. The duty of constraint (16) is that, in connection with constraint (15), only one of the logical variables can take the value one, while the other one takes the value zero. The possible values of the logical variables in constraint (17) are determined by using the constraints (14a), (14b), (15), and (16).

If a satisficing level $S L_{j}$ is determined for the respective output, the normalized output quantities $a_{i j}$ are obtained by applying the constraints (14a), (14b), (15), (16), and (17). These quantities are necessary for making up the normalized output matrix $\underline{A}$. However, if no satisficing level is established for an output $j$, the respective column vector $\vec{a}_{j}$ in the matrix $\underline{A}$ is equal to the column vector $\overrightarrow{\vec{r}}_{j}$ in the matrix $\underline{R}$.

$$
\underline{A}=\left[\begin{array}{cccc}
a_{11} & a_{12} & \ldots & a_{1 J} \\
a_{21} & a_{22} & \ldots & a_{2 J} \\
\vdots & \vdots & \vdots & \vdots \\
\vdots & \vdots & \vdots & \vdots \\
\vdots & \vdots & \vdots & \vdots \\
a_{I 1} & a_{I 2} & \ldots & a_{I J}
\end{array}\right]
$$

Next, the determination of the maximum normalized output quantity $a_{j}^{*}$ is realized for each output $j$ by taking the maximum value of each column vector $\overrightarrow{a_{j}}$.

$$
a_{j}^{*}=\max _{i}\left\{\overrightarrow{a_{j}}\right\} \quad \forall j=1, \ldots, J
$$

The maximum normalized output quantity $a_{j}^{*}$ is used to calculate the distance measures for outputs. This distance measure is calculated for all DMUs $i$ and for all outputs $j$.

$$
o p_{i j}^{S L}=1-\left(a_{j}^{*}-a_{i j}\right) \quad \forall i=1, \ldots, I \quad \forall j=1, \ldots, J
$$

An efficiency score is calculated for each DMU, as before. But this time, $E_{i}^{S L}$ incorporates the distance measures $o p_{i j}^{S L}$ in order for the satisficing levels for the outputs to be considered.

$$
E_{i}^{S L}=\frac{\sum_{j=1}^{J} v_{j * o p}{ }_{i j}^{S L}}{\sum_{k=1}^{K} w_{k}^{*} i_{i k}} \quad \forall i=1, \ldots, I
$$

By sorting the efficiency scores $E_{i}^{S L}$ from high to low, a rank order $R^{S L}$ of the efficiency of the DMUs can be obtained once again.

\subsection{Operational Competitiveness Rating}

Operational Competitiveness Rating (OCRA) is a simple and convenient method developed by Parkan (1994) to solve performance and efficiency analysis problems. OCRA is used in the measurement of the relative efficiency of the Product Units (PU) producing similar outputs by using similar inputs. OCRA has been implemented in various areas successfully, such as investment banking, performance measurement of service buildings of public institutions, industrial enterprises, hotels and food production facilities (Peters \& Zelewski, 2010).

The general OCRA procedure is described as below (Parken \& Wu, 2000; Chatterjee \& Chakraborty, 2012): OCRA method is only concerned with the scores that various alternatives receive for the input attribute without considering the scores received for the beneficial attribute. The lower values of non-beneficial or input criteria are more preferable. The total performance of $i t h$ alternative with respect to the entire input attribute is calculated using the following equation (22):

$$
i^{k}=\sum_{m=1}^{M} a_{m} \frac{\max _{n=1, \ldots, K}\left(X_{m}^{n}\right)-X_{m}^{k}}{\min _{n=1, \ldots, K}\left(X_{m}^{n}\right)}, k=1, \ldots, K
$$

The rating $i^{k}$ measures the relative performance of the $k t h \mathrm{PU}$ or the preference for the alternative $k . X_{m}^{k}$ is the perceived performance score of the alternative $k$, on, for example, five or nine-point scale, for input criterion $m$. The subindex $m$ in (22) refers to input criterion $m=1, \ldots, M$ and $k$ refers to the alternative $k=1, \ldots, K$. The 
calibration constant $a_{m}$ (relative importance of $j t h$ criterion) is used to increase or reduce the impact of this difference on the rating $i^{k}$ with respect to $j$ th criterion.

The ratings $i^{k}$ are scaled linearly, so a zero rating can be assigned to the least preferable alternative by using the following equation:

$$
I^{k}=i^{k}-\min _{n=1, \ldots, K} i^{n}, \quad \forall k=1, \ldots, K
$$

$I^{k}$ represents the aggregate preference rating for alternative $k$ with respect to the input criteria.

In a manner similar to the input preference rating computations, inputs are not included in this step. The aggregate performance or the preference of the decision maker for alternative $k$, on all the output criteria is measured as follows:

$$
o^{k}=\sum_{h=1}^{H} b_{h} \frac{Y_{h}^{k}-\min _{n=1, \ldots, K} Y_{h}^{n}}{\min _{n=1, \ldots, K} Y_{H}^{n}}, \quad k=1, \ldots, K
$$

The subindex $h$ in (24) refers to output $h=1, \ldots H . Y_{h}^{k}$ is the performance score the alternative $k$ receives for the output criterion $h$ using the same scale as the input scores. The higher an alternative's score for an output criterion, the higher is the preference for that alternative. $b_{h}$ is calibration constant or weight importance of $j t h$ output criteria. The higher an alternative's score for an output criterion, the higher is the preference for that alternative. It can be mentioned that

$$
\sum_{m=1}^{M} a_{m}+\sum_{h=1}^{H} b_{h}=1
$$

In order to obtain a zero rating for the least preferable alternative, the ratings calculated by (26) are scaled linearly.

$$
O^{k}=o^{k}-\min _{n=1, \ldots, K} o^{n}, \quad \forall k=1, \ldots, K
$$

$O^{k}$ is the preference rating of alternative $k$ with respect to the output criteria.

The overall preference rating for alternative $\mathrm{k}$ is obtained by scaling the sum $I^{k}=O^{k}$ so that the least preferable alternative receives a rating of zero. The overall preference rating $E^{k}$ is calculated as follows:

$$
E^{k}=\left(I^{k}+O^{k}\right)-\min _{n=1, \ldots, K}\left(I^{n}+O^{n}\right), \quad \forall k=1, \ldots, K
$$

The alternatives are ranked according to the values of the overall preference rating. The alternative with the highest overall performance rating receives the first rank.

\section{Data and Discusion}

The efficiency model introduced was used to analyze the efficiency of TRC between 2012 and 2014. "Total Revenues" and "Total Expenses" were taken as inputs while "the Total Expense for Goals and Services" and "Surplus Income" were defined as the output criteria.

In the application of EATWOS, each criteria weight was taken as 0,5 while it was taken as 0,25 in the application of OCRA. The data used in the model, shown in Table1 below, were obtained from the official website of TRC (kizilay.org.tr). The flow chart of the model is given in Figure 1.

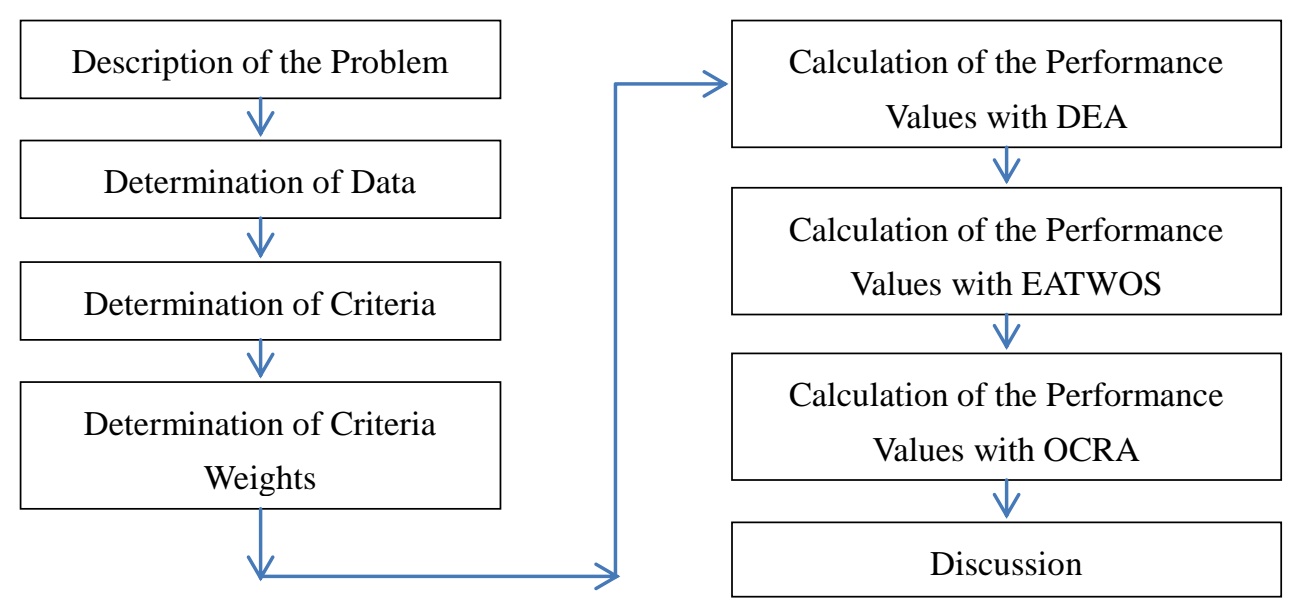

Figure 1. The flow chart of the model 
Table 1. Inputs and outputs

\begin{tabular}{ccccc}
\hline \multirow{2}{*}{ Year } & \multicolumn{2}{c}{ Inputs } & \multicolumn{2}{c}{ Outputs } \\
\cline { 2 - 5 } & Total Revenues (US\$) & Total Expenses (US\$) & Total Expense for Goals and Services (US\$) & Surplus Income (US\$) \\
\hline 2012 & 176.289 .874 & 114.359 .116 & 47.104 .900 & 14.825 .858 \\
2013 & 181.324 .553 & 112.596 .596 & 48.343 .151 & 20.384 .807 \\
2014 & 206.673 .432 & 120.429 .697 & 67.811 .502 & 18.432 .233 \\
\hline
\end{tabular}

\subsection{The Application of the DEA Method}

The scale used in the study was 'constant returns to scale'. Separate analyses were performed for each year. The data shown in Table 1 were analyzed by DEA, and the results shown in Table 2 were obtained. In the light of the analysis of the results it could be said that TRC showed inefficient performance in 2012 while it continued its operations efficiently in 2013 and 2014.

Table 2. Efficiency scores of TRC according to DEA

\begin{tabular}{cccc}
\hline & 2012 & 2013 & 2014 \\
\hline DEA & 0,87 & 1,00 & 1,00 \\
\hline
\end{tabular}

\subsection{The Application of the EATWOS Method without Consideration of Satisficing Levels}

Utilizing the data given in Table 2, EATWOS method was applied without consideration of satisficing levels. Criteria weights for each input and output were taken as 0,5. The equation (5a) was employed for the normalization of input and output quantities. The normalized data were shown in Table 3.

Table 3. The normalized input and output quantities

\begin{tabular}{ccccc}
\hline \multirow{2}{*}{ Year } & \multicolumn{2}{c}{ Inputs $(\underline{\mathrm{S}})$} & \multicolumn{2}{c}{ Outputs $(\mathrm{R})$} \\
\cline { 2 - 5 } & Total Revenues & Total Expenses & Total Expense for Goals and Services & Surplus Income \\
\hline 2012 & 0,5398 & 0,5700 & 0,4923 & 0,4748 \\
2013 & 0,5552 & 0,5612 & 0,5053 & 0,6528 \\
2014 & 0,6328 & 0,6002 & 0,7087 & 0,5903 \\
\hline
\end{tabular}

In the calculation of output distance measures, equations (7) and (8) were used while equations (11) and (12) were employed for the calculation of input distance measures.

Table 4. Input and output distance measures

\begin{tabular}{lllll}
\hline Year & \multicolumn{2}{c}{ Input } & \multicolumn{2}{c}{ Output } \\
\hline 2012 & 1,0000 & 1,0088 & 0,7836 & 0,8220 \\
2013 & 1,0154 & 1,0000 & 0,7965 & 1,0000 \\
2014 & 1,0930 & 1,0390 & 1,0000 & 0,9375 \\
\hline
\end{tabular}

By using equation (13), the efficiency score for each DMU was obtained with the help of input distance measures and output distance measures. The efficiency scores and the normalized efficiency scores are given in Table 5.

Table 5. Efficiency scores and the normalized efficiency scores

\begin{tabular}{lcc}
\hline Year & Efficiency Scores & Normalized Efficiency Scores \\
\hline 2012 & 0,7993 & 0,3077 \\
2013 & 0,8914 & 0,3423 \\
2014 & 0,9087 & 0,3500 \\
\hline
\end{tabular}

According to the results given in Table 5, TRC performed its operations efficiently in 2013 and 2014, but this is 
not true for the year 2012 .

\subsection{The Application of the EATWOS Method with Consideration of Satisficing Levels}

Utilizing the data given in Table 2, EATWOS method was applied with consideration of satisficing levels. The satisficing level for the output "Total Expense for Goals and Services" is determined as $S L_{1}=56.600 .000$, so the logical constraints, presented in equations (14a), (14b), (15), (16) and (17) have to be applied to this output. The input and output values normalized by EATWOS with consideration of "Satisficing" levels are shown in Table 6.

Table 6. The normalized input and output quantities with consideration of SL

\begin{tabular}{ccccc}
\hline & \multicolumn{2}{c}{ Input $(\underline{\mathrm{S}})$} & \multicolumn{2}{c}{ Output $(\mathrm{R})$} \\
\cline { 2 - 5 } Year & Total Revenues & Total Expenses & Total Expense for Goals and Services & Surplus Income \\
\hline 2012 & 0,5398 & 0,5700 & 0,8322 & 0,4748 \\
2013 & 0,5552 & 0,5612 & 0,8541 & 0,6528 \\
2014 & 0,6328 & 0,6002 & 1,0000 & 0,5903 \\
\hline
\end{tabular}

The output distance measures were calculated by equations (19) and (20) while the input distance measures were calculated by equations (11) and (12).

Table 7. Input and output distance measures with consideration of SL

\begin{tabular}{ccccc}
\hline Year & \multicolumn{2}{c}{ Input } & \multicolumn{2}{c}{ Output } \\
\hline 2012 & 1,0000 & 1,0088 & 0,8322 & 0,8220 \\
2013 & 1,0154 & 1,0000 & 0,8541 & 1,0000 \\
2014 & 1,0930 & 1,0390 & 1,0000 & 0,9375 \\
\hline
\end{tabular}

By using equation (21), the efficiency score for each DMU was obtained with the help of input and output distance measures. The efficiency score and the normalized efficiency score are given in Table 8.

Table 8. Efficiency scores and the normalized efficiency scores with consideration of SL

\begin{tabular}{ccc}
\hline Year & Efficiency Scores & Normalized Efficiency Scores \\
\hline 2012 & 0,8235 & 0,3105 \\
2013 & 0,9200 & 0,3469 \\
2014 & 0,9087 & 0,3426 \\
\hline
\end{tabular}

According to the analysis of the results given in Table 8, TRC showed a higher performance in 2013 than in 2012 and 2014.

\subsection{The Application of OCRA}

As in DEA and EATWOS, in the application of OCRA also, the data in Table 2 was used for analysis. The scaled input and output indexes and performance scores are shown in Table 9.

Table 9. Efficiency scores and the normalized efficiency scores

\begin{tabular}{ccccc}
\hline Year & Input & Output & Efficiency Scores & Normalized Efficiency Scores \\
\hline 2012 & 0,0566 & 0,000 & 0,0566 & 0,1485 \\
2013 & 0,0533 & 0,1003 & 0,1536 & 0,4034 \\
2014 & 0,0000 & 0,1707 & 0,1707 & 0,4481 \\
\hline
\end{tabular}

As Table 9 indicates, the year with highest performance for TRC was 2014 according to OCRA results. The year 2012 was less efficient. Table 10 gives all the efficiency scores for each method: DEA, EATWOS without SL, EATWOS with SL and OCRA. All the methods say that TRC showed lower performance in 2012 than in 2013 and 2014. The study also show that the efficiency ratings were similar in 2013 and 2014. 
Table 10. Efficiency scores

\begin{tabular}{lcccc}
\hline Year & DEA & EATWOS & EATWOS with SL & OCRA \\
\hline 2012 & 0,3027 & 0,3077 & 0,3100 & 0,1485 \\
2013 & 0,3487 & 0,3423 & 0,3500 & 0,4000 \\
2014 & 0,3487 & 0,3500 & 0,3400 & 0,4500 \\
\hline
\end{tabular}

As Figure 2 shows that DEA, EATWOS and EATWOS with SL resulted in very similar scores, while OCRA showed a very slight difference. To conclude, 2013 and 2014 were efficient years for TRC.

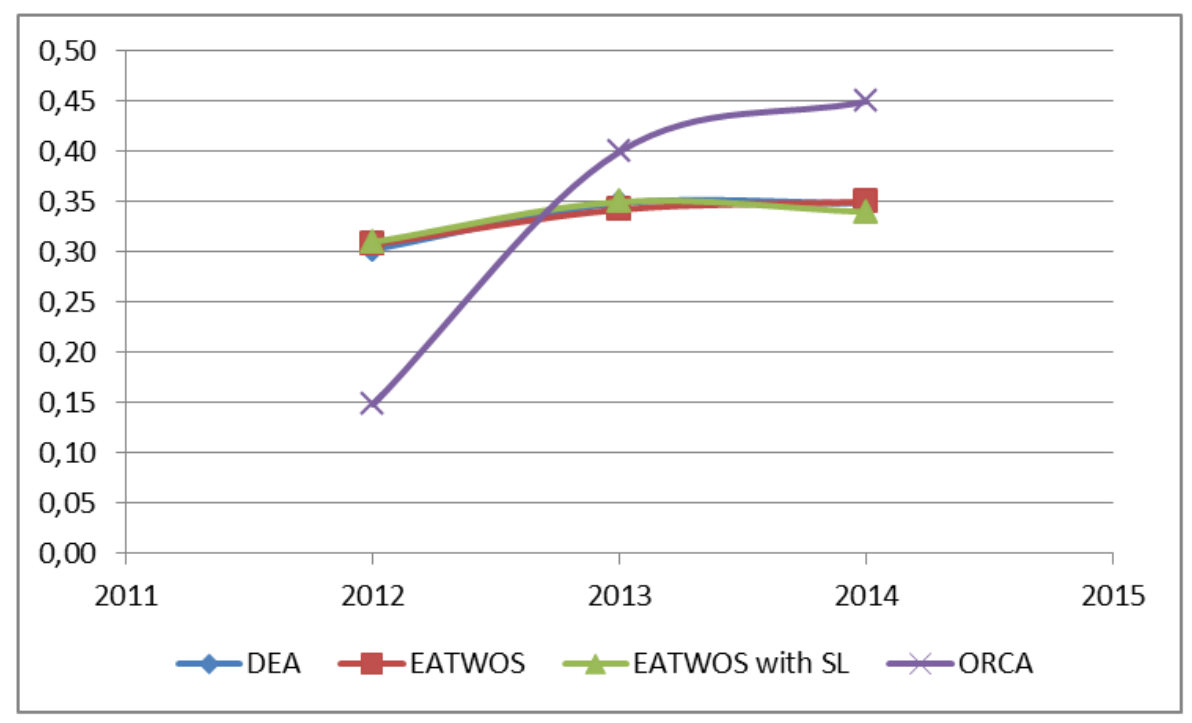

Figure 2. Efficiency scores

\section{Conclusion}

Like businesses, NGOs must also work with efficiency. If they perform badly, it is difficult for them to be able to keep up. This means it is necessary for NGOs to go through efficiency analyses as well regularly. This study was carried to measure the efficiency of TRC between 2012 and 2014. Of the evaluation criteria used in the study, "Total Revenues" and "Total Expenses" were taken as inputs while "the Total Expense for Goals and Services" and "Surplus Income" were defined as the output criteria. The analyses with all methods showed that TRC performed better in 2013 and 2014. All the results again indicated that the 2012 was the least efficient year. 2014 was a better year than 2013 according to OCRA results while the other methods proved no significant differences. Though the results say that TRC have had a better performance in recent years, as the author of this articlae, I believe that it is still not good enough because only $33 \%$ of the total incomes are used for the social purposes. This should at least be increased to $40 \%$. In order to do that, TRC needs to take necessary financial and structural measures without any delay.

\section{References}

Ahmed, S. Z. (2010). Measuring performance and impact of rural community-led library initiatives in Thailand. Information Development, 26(1), 17-35. http://dx.doi.org/10.1177/0266666909358296

Arena, M., Azzone, G., \& Bengo, I. (2015). Performance Measurement for Social Enterprises. VOLUNTAS: International Journal of Voluntary and Nonprofit Organizations, 26(2), 649-672. http://dx.doi.org/10.1007/s11266-013-9436-8

Bagnoli, L. (2009). Performance measuring in social enterprises. Second EMES International Conference on Social Enterprise, Trento.

Bagnoli, L., \& Megali, C. (2011). Measuring performance in social enterprises. Nonprofit and Voluntary Sector Quarterly, 40(1), 149-165. http://dx.doi.org/10.1177/0899764009351111

Bai-qing, Y., \& Tai-ping, G. (2009). Study on the Disaster Crisis Management Performance Evaluation of Non-governmental Organizations. 5th International Conference on Public Administration, 1, 423-427. 
Bansal, A., Kr. Singh, R., Issar, S., \& Varkey, J. (2014). Evaluation of vendors ranking by EATWOS approach. Journal of Advances in Management Research, 11(3), 290-311. http://dx.doi.org/10.1108/JAMR-02-2014-0009

Berber, P., Brockett, P. L., Cooper, W. W., Golden, L. L., \& Parker, B. R. (2011). Efficiency in fundraising and distributions to cause-related social profit enterprises. Socio-Economic Planning Sciences, 45(1), 1-9. http://dx.doi.org/10.1016/j.seps.2010.07.007

Blaakman, A. P., Salehi, A. S., \& Boitard, R. (2014). A cost and technical efficiency analysis of two alternative models for implementing the basic package of health services in Afghanistan. Global Public Health, 9(sup1), 110-123. http://dx.doi.org/10.1080/17441692.2013.829862

Bouchard, J. M. (2009a). The worth of the social economy. In J. M. Bouchard (Ed.), The worth of the social economy: An international perspective (pp. 11-18). Brussels: P.I.E. Peter Lang.

Bouchard, J. M. (2009b). The evaluation of the social economy in Quebec, with regards to stakeholders, mission and organizational identity. In J. M. Bouchard (Ed.), The worth of the social economy: An international perspective (pp. 111-132). Brussels: P.I.E. Peter Lang.

Bull, M. (2007). Balance: The development of a social enterprise business performance analysis tool. Social Enterprise Journal, 3, 49-66. http://dx.doi.org/10.1108/17508610780000721

Campos, L., Andion, C., Serva, M., Rossetto, A., \& Assumpção, J. (2011). Performance evaluation in non-governmental organizations (NGOs): An analysis of evaluation models and their applications in Brazil. VOLUNTAS: International Journal of Voluntary and Nonprofit Organizations, 22(2), 238-258. http://dx.doi.org/10.9790/487X-17237076

Chakraborty, R., Ray, A., \& Dan, P. (2013). Multi criteria decision making methods for location selection of distribution centers. International Journal of Industrial Engineering Computations, 4(4), 491-504. http://dx.doi.org/10.5267/j.ijiec.2013.06.006

Charnes, A., Cooper, W. W., \& Rhodes, E. (1978). Measuring the efficiency of decision making units. Eur. J. Oper. Res., 2, 429-444. http://dx.doi.org/10.1016/0377-2217(78)90138-8

Chatterjee, P., \& Chakraborty, S. (2012). Material selection using preferential ranking methods. Materials \& Design, 35, 384-393. http://dx.doi.org/10.1016/j.matdes.2011.09.027

Cooper, W. W., Seiford, L. M., \& Zhu, Joe. (2011). Handbook on data envelopment analysis. NY: Springer. Economic Review, 69(4), 493-513.

Darji, V. P., \& Rao, R. V. (2014). Intelligent Multi Criteria Decision Making Methods for Material Selection in Sugar Industry. Procedia Materials Science, 5, 2585-2594. http://dx.doi.org/10.1016/j.mspro.2014.07.519

Ebrahim, A., \& Rangan, V. K. (2011). Performance measurement in the social sector: A contingency framework. Social Enterprise Initiative, Harvard Business School, working paper.

Eme, B. (2009). Miseries and worth of the evaluation of the social and solidarity-based economy: For a paradigm of communicational evaluation. In J. M. Bouchard (Ed.), The worth of the social economy: An international perspective (pp. 63-86). Brussels: P.I.E. Peter Lang.

Fowler, A. (1996). Assessing NGO performance: difficulties, dilemmas and a way ahead. Beyond the magic bullet: NGO performance and accountability in the post-Cold War world, 169-187.

Greiling, D. (2009). Performance Measurement in Nonprofit-Organisationen. Springer-Verlag.

Gutierrez-Nieto, B., Serrano-Cinca, C., \& Molinero, C. M. (2007). Microfinance institutions and efficiency. Omega, 35(2), 131-142. http://dx.doi.org/10.1016/j.omega.2005.04.001

Hall, M. (2014). Evaluation logics in the third sector. VOLUNTAS: International Journal of Voluntary and Nonprofit Organizations, 25(2), 307-336. http://dx.doi.org/10.1007/s11266-012-9339-0

Haq, M., Skully, M., \& Pathan, S. (2010). Efficiency of microfinance institutions: A data envelopment analysis. Asia-Pacific Financial Markets, 17(1), 63-97. http://dx.doi.org/10.1007/s10690-009-9103-7

Hwang, C. L., \& Yoon, K. (1981). Multiple Attribute Decision Making-Methods and Applications-A State-of-the-Art Survey. Berlin, Heidelberg, New York 1981, p. 128.

Jayanthi, S., Kocha, B., \& Sinha, K. K. (1999). Competitive analysis of manufacturing plants: An application to the US processed food industry. European Journal of Operational Research, 118(2), 217-234. http://dx.doi.org/10.1016/S0377-2217(99)00022-3 
Kaplan, R. S. (2001). Strategic performance measurement and management in third sector organizations. Nonprofit Management and Leadership, 11(3), 353-371.

Kaplan, R. S., \& Norton, D. P. (1996) The Balanced Scorecard-Translating Strategy into Action. Boston, MA: Harvard Business School Press.

Kirigia, J. M., Emrouznejad, A., Sambo, L. G., Munguti, N., \& Liambila, W. (2004). Using data envelopment analysis to measure the technical efficiency of public health centers in Kenya. Journal of Medical Systems, 28(2), 155-166. http://dx.doi.org/10.1023/B:JOMS.0000023298.31972.c9

Kirigia, J. M., Sambo, L. G., Renner, A., Alemu, W., Seasa, S., \& Bah, Y. (2011). Technical efficiency of primary health units in Kailahun and Kenema districts of Sierra Leone. International Archives of Medicine, 4(1), 15. http://dx.doi.org/10.1186/1755-7682-4-15

Kolb. D. A., \& Fry, R. (1975) Toward an applied theory of experiential learning. In C. Cooper (Ed.), Theories of Group Process. London: John Wiley.

LaPlante, A. E., \& Paradi, J. C. (2015). Evaluation of bank branch growth potential using data envelopment analysis. Omega, 52, 33-41. http://dx.doi.org/10.1016/J.OMEGA.2014.10.009

Lépine, A., Vassall, A., \& Chandrashekar, S. (2015). The determinants of technical efficiency of a large scale HIV prevention project: Application of the DEA double bootstrap using panel data from the Indian Avahan. Cost Effectiveness and Resource Allocation, 13(1), 5. http://dx.doi.org/10.1186/s12962-015-0031-2

Makni, R., Benouda, O., \& Delhoumi, E. (2015). Large scale analysis of Islamic equity funds using a meta-frontier approach with data envelopment analysis. Research in International Business and Finance, 34, 324-337. http://dx.doi.org/10.1016/j.ribaf.2015.02.014

Murray, V., \& Tassie, B. (1995). Evaluating the efectiveness of nonprofit organizations. In Jossey-Bass handbook of nonprofit leadership and management (pp. 303-324). San Francisco: Jossey-Bass.

Nanavati, A. (2007). Performance Evaluation of Non-government Development Organisations A Study in

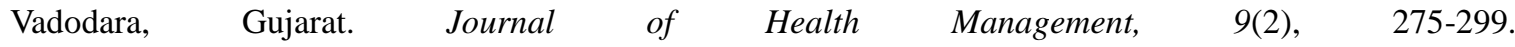
http://dx.doi.org/10.1177/097206340700900208

Özbek, A. (2015). Performance Analysis of Public Banks in Turkey. International Journal of Business Management and Economic Research (IJBMER), 6(3),178-186.

Özdemir, A., \& Demireli, E. (2013). Ağırlık Kısıtlı Veri Zarflama Analizi İle Mevduat Bankalarının Etkinlik Ölçümüne Yönelik Bir Uygulama. Uluslararası Yönetim İktisat ve İşletme Dergisi, 9(19), 215-238.

Parkan, C. (1999). Performance measurement in government services. Managing Service Quality: An International Journal, 9(2), 121-135. http://dx.doi.org/10.1108/09604529910257911

Parkan, C. (2002). Measuring the operational performance of a public transit company. International Journal of Operations \& Production Management, 22(6), 693-720. http://dx.doi.org/10.1108/01443570210427695

Parkan, C. (2003). Measuring the effect of a new point of sale system on the performance of drugstore operations. Computers \& Operations Research, 30(5), 729-744. http://dx.doi.org/10.1016/S0305-0548(02)00047-3

Parkan, C., \& Wang, J. (2007). Gauging the performance of a supply chain. International Journal of Productivity and Quality Management, 2(2), 141-176. http://dx.doi.org/10.1504/IJPQM.2007.012408

Parkan, C., \& Wu, M. L. (1997). On the equivalence of operational performance measurement and multiple attribute decision making. International Journal of Production Research, 35(11), 2963-2988. http://dx.doi.org/10.1080/002075497194246

Parkan, C., \& Wu, M. L. (1998). Process selection with multiple objective and subjective attributes. Production Planning \& Control, 9(2), 189-200. http://dx.doi.org/10.1080/095372898234415

Parkan, C., \& Wu, M. L. (1999a). Decision-making and performance measurement models with applications to robot selection. Computers \& Industrial Engineering, 36(3), 503-523. http://dx.doi.org/10.1016/S0360-8352(99)00146-1

Parkan, C., \& Wu, M. L. (1999b). Measurement of the performance of an investment bank using the operational $\begin{array}{lllll}\text { competitiveness } & \text { rating }\end{array}$ http://dx.doi.org/10.1016/S0305-0483(98)00041-3

Parkan, C., Lam, K., \& Hang, G. (1997). Operational competitiveness analysis on software development. Journal of the Operational Research Society, 48(9), 892-905. http://dx.doi.org/10.1002/mde.4090150303 
Paul, B. K. (2003). Relief assistance to 1998 flood victims: A comparison of the performance of the government and NGOs. The Geographical Journal, 169(1), 75-89. http://dx.doi.org/10.1111/1475-4959.04958

Peters, M. L., \& Zelewski, S. (2006). Efficiency analysis under consideration of satisficing levels for output quantities. In Proceedings of the 17th Annual Conference of the Production and Operations Management Society (POMS), 28(1.05).

Peters, M. L., \& Zelewski, S. (2010). Analyse der Effizienzentwicklung von Bankfilialen mithilfe des Operational Competitiveness Ratings (OCRA). PIM. Retrieved June 15, 2015, from https://www.pim.wiwi.uni-due.de/uploads/tx_itochairt3/publications/Peters_Zelewski_-_OCRA.pdf

Peters, M. L., Zelewski, S., \& Bruns, A. S. (2012). Extended Version of EATWOS concerning Satisficing Levels for Input Quantities. Pioneering Supply Chain Design: A Comprehensive Insight Into Emerging Trends. Technologies and Applications, 10, 303.

Ramadan, M. A., \& Borgonovi, E. (2015). Performance Measurement and Management in Non-Governmental Organizations, IOSR Journal of Business and Management (IOSR-JBM), 70-76. http://dx.doi.org/10.9790/487X-17237076

Saaty, T. L. (2004). Decision Making-The Analytic Hierarchy and Network Processes (AHP/ANP). Journal of System Science and Systems Engineering, 13(1), 1-35.

Simon, H. A. (1979). Rational Decision Making in Business Organizations (p. 495).

Turkish Red Crescent Society. (n. d.). Retrieved June 15, 2015, from http://www.kizilay.org.tr/kurumsal/tarihcemiz

Widiarto, I., \& Emrouznejad, A. (2015). Social and financial efficiency of Islamic microfinance institutions: A data envelopment analysis application. Socio-Economic Planning Sciences, 50, 1-17. http://dx.doi.org/10.1016/j.seps.2014.12.001

Wijesiri, M., Viganò, L., \& Meoli, M. (2015). Efficiency of microfinance institutions in Sri Lanka: A two-stage double bootstrap DEA approach. Economic Modelling, 47, 74-83. http://dx.doi.org/10.1016/j.econmod.2015.02.016

Yan, H., Yu, Z., \& Cheng, T. C. E. (2003). A strategic model for supply chain design with logical constraints: formulation and solution. Computers \& Operations Research, 30(14), 2135-2155. http://dx.doi.org/10.1016/S0305-0548(02)00127-2

\section{Copyrights}

Copyright for this article is retained by the author(s), with first publication rights granted to the journal.

This is an open-access article distributed under the terms and conditions of the Creative Commons Attribution license (http://creativecommons.org/licenses/by/3.0/). 